Est Ag 54 (2019) 185-220

\title{
De la catequesis escolar a la enseñanza religiosa en la escuela y la catequesis de la comunidad cristiana
}

Álvaro GINEL, SDB

Resumen: El artículo pretende presentar el paso que la Iglesia española realiza, en un espacio de tiempo muy reducido, de una concepción de la catequesis entendida como "catequesis escolar" a una realidad nueva: "enseñanza religiosa en la escuela" y "catequesis de la comunidad". La Iglesia española que había permanecido al margen del "movimiento de renovación catequética" operado en el entorno del Concilio Vaticano II, tuvo que adaptarse con rapidez presionada por dos acontecimientos: eclesial y político. Eclesial: la renovación puesta en marcha por el Concilio y concretada en los Sínodos de 1974 y de 1977 y las Exhortaciones apostólicas que de ellos emanaron. Político: el paso de una forma política de dictadura que favorecía en algunos aspectos la enseñanza a la Iglesia, a un régimen de democracia donde la Iglesia comenzó a ser cuestionada justo en aquel lugar que había sido su mejor ámbito de catequesis: la escuela.

Palabras claves: Catequesis. Catequesis escolar. Enseñanza religiosa. Catequista. Historia de la catequesis en España.

Abstract: The article aims to present the step that the Spanish Church takes, in a very short space of time, from a conception of catechesis understood as "school catechesis" to a new reality: "religious teaching in school" and "community catechesis " The Spanish Church that had remained outside the "catechetical renewal movement" operated in the surroundings of the Second Vatican Council, had to adapt quickly under pressure from two events: ecclesial and political. Ecclesial: the renewal set in motion by the Council and concretized in the Synods of 1974 and 1977 and the apostolic Exhortations that emanated from them. Political: the passage of a politi- 
cal form of dictatorship that favored in some aspects the teaching to the Church, to a regime of democracy where the Church began to be questioned right in that place that had been its best area of catechesis: the school.

Keywords: Catechesis, School Catechesis, Religious education, Catechist, History of catechesis in Spain.

Se me ha invitado a una colaboración en el homenaje al querido Don Luis Resines. Lo hago con mucho gusto y reconocimiento al trabajo callado de Luis. Me hubiera gustado entrar en el acervo de datos que él ha ido recopilando a lo largo de años especialmente en las bibliotecas de la ciudad que ha sido escenario de su investigación, Valladolid. Creo que pocos historiadores de la catequesis disponen de un material catequético para la historia de la catequesis como el que Luis ha logrado reunir, sobre todo en catecismos, no solo los editados en España, sino los que muchos misioneros españoles elaboraron en América Latina y en Filipinas ${ }^{1}$.

${ }^{1}$ LuIs Resines Llorente: Obras en relación con el tema tratado.

- Catecismos de Astete y Ripalda, BAC, Madrid 1987.

- Historia de la catequesis en España, Editorial CCS, Madrid 1995.

- La catequesis en España: historia y textos, BAC, Madrid 1997.

- De la fe maltratada a la fe bientratada, PPC, Madrid 2009.

- Doctrina cristiana, Ediciones de la Diputación de Salamanca, Salamanca 1991.

- Obra y pensamiento catequético de Daniel Llorente, Valladolid 1981. Tesis de doctorado.

Luis Resines Llorente: Los Catecismos.

- Doctrina cristiana muy útil y necesaria: México 1578, Universidad de Salamanca, Salamanca 1990.

- Catecismos americanos del siglo XVII, tomo I, Junta de Castilla y León. Consejería de Cultura y Turismo, Valladolid 1992.

- Las raíces cristianas de América, CELAM. Santafé de Bogotá (Colombia) 1993.

- Hernando de Talavera, prior del Monasterio de Prado, Junta de Catilla y León. Consejería de Cultura y Turismo, Valladolid, 1993.

- Catecismo del Sacromonte y Doctrina christiana del Fr. Pedro de Feria: conversión y evangelización de moriscos e indios, Consejo Superior de Investigaciones Científicas, Madrid 2002.

- Catecismo breve de Fray Pedro Vives (edición crítica), Ajuntament de Valencia, Valencia 2002.

- Catecismos pictóricos de Pedro de Gante, incompleto y Mucagua, Fundación Universitaria Española, Madrid 2007. 
Mi contribución, sin embargo, se centra en un momento muy concreto y rico de la historia de la catequesis española que Luis conoce muy bien: el tiempo que va entre la publicación del documento La enseñanza religiosa es$\operatorname{colar}^{2}$ (1969) que supuso el inicio de una manera de concebir la catequesis en la escuela y 1985 fecha en la que sale al público El catequista y su formación $n^{3}$, que consagra a la comunidad cristiana como lugar de la catequesis y al catequista como principal agente de la catequesis. En el centro de este periodo tenemos la publicación de la "obra cumbre" del magisterio de la Iglesia española sobre la catequesis, La catequesis de la comunidad (febrero 1983). Completa la trilogía de grandes documentos catequéticos de la Iglesia en España el publicado en 1990 Catequesis de adultos ${ }^{4}$ (diciembre 1990).

Mi reflexión es continuación de otro trabajo: Una década crucial para la historia de la catequesis en España: los años $70^{5}$. Me ciño al análisis interno de los documentos eclesiales con mínimas alusiones a la apasionante transformación que vive la sociedad española en la década de los setenta cuyo culmen es la aprobación de la Constitución Española (1978). Reconozco la limitación de mi aportación. Simplemente pretendo resaltar cómo la Iglesia española en una década pasa de la catequesis "tradicional" (la del catecismo de Astete y Ripalda), al menos en los documentos eclesiales, otra cosa es la implantación práctica, a una catequesis abierta al postconcilio.

\section{UN TELÓN DE FONDO}

Para poder captar el sentido de lo que pasa en la catequesis española, al menos desde la perspectiva teórica, en el espacio breve de los años 1979-

- Diccionario de los catecismos pictográficos, Diputación de Valladolid, Valladolid 2007.

- El catecismo de Pedro Ramiro de Alba, Universidad de Granada, Granada 2015.

Para rastrear la obra catequética de Luis RESINES LLORENTE hay que acudir a la revista "Estudio agustiniano" (ISSN 0425-340X), al "Archivo agustiniano" (ISSN 0211-2035), donde se encontrarán muchos estudios.

${ }^{2}$ Comisión Episcopal de EnseñanZa y CATEQuesis, Orientaciones pastorales sobre la Enseñanza Religiosa Escolar. Su legitimidad, carácter propio y contenido, Edice, Madrid 1979.

${ }^{3}$ Comisión Episcopal de Enseñanza y CATequesis, El catequista y su formación. Orientaciones pastorales, EDICE, Madrid 1985.

${ }^{4}$ Comisión Episcopal de Enseñanza y CATequesis, Catequesis de adultos. Orientaciones pastorales, EDICE, Madrid 1991.

${ }^{5}$ Álvaro Ginel, Una década crucial para la historia de la catequesis en España: los años 70, en “Sínite”, vol. LI, 154-155 (2010) 407-437. 
1985, es bueno tener en cuenta el humus que está en el inmediato periodo anterior. Nos fijamos en dos elementos: la catequesis en la escuela y el maestro, como principales elementos que sustentan la catequesis. Los acontecimientos históricos y la respuesta, muchas veces obligada, que la Iglesia tiene que dar, harán que todo cambie muy rápidamente: que la escuela deje de ser "lugar catequético" y la comunidad cristiana se entienda de manera nueva como "origen y meta" de la catequesis. Además, la exigencia de nuevos métodos en la escuela impondrá una renovación a la misma catequesis.

\section{La escuela como lugar principal de la catequesis}

En este periodo, entiéndase los sesenta primeros años del siglo XX, el lugar fundamental de la catequesis está en la escuela y "el primer catequista de la parroquia debe ser el maestro"6. No se trata de que la catequesis repita las lecciones que ya se han dado en la escuela, sino de que los maestros, en su tarea escolar, son los grandes ayudantes del párroco en la catequesis. Muchas parroquias no sienten la necesidad de tener catequesis porque esta ya se imparte en el lugar de socialización de la educación: la escuela.

Existe toda una visión unitaria donde la escuela y la parroquia se complementan y apoyan mutuamente. Se habla y recuerda la asistencia obligatoria, en corporación, de todos los niños y maestros de las escuelas nacionales, en los días de precepto, a la misa parroquial, fijada a la hora conveniente de acuerdo con la autoridad eclesiástica ${ }^{7}$. Una uniformidad y globalidad de ordenamiento de vida cristiana que, aunque no fuera seguido de manera generalizada, está ahí y es síntoma de cómo se entiende al "maestro catequista". El ideal consiste en que todos los niños católicos reciban en la escuela la correspondiente enseñanza religiosa ${ }^{8}$.

\footnotetext{
${ }^{6}$ Serrano de Raro, A., Párrocos y escuelas, en "Boletín nacional de informaci6n catequística" 7 (1961) 10. TusQueTs, J., La función catequística del maestro, en "Bordón" 36 (1953) 339-355. Este autor ve al maestro como quien se propone "que el alumno esté pertrechado, al finalizar la etapa instructiva, con los conocimientos que necesita para avanzar con seguro paso hacia el último fin", cfr. p. 339. Se pide al maestro "vida interior intachable", "vivir en estado de gracia", "sentir el apostolado religioso" y desarrollarlo como "hijo ejemplar de la Iglesia", cfr. p. 340.

${ }^{7}$ Serrano de Raro, A., Párrocos y escuelas, en "Boletín nacional de información catequística" 9 (1961) 8-9.

${ }^{8}$ Mencía, G., El acento de la actividad catequística en España ¿no debería ponerse más en la catequesis escolar?, en "Sinite" vol. 5 (1964) 191-216; especialmente aquí la p. 198. EsTEPA
} 
La catequesis parroquial se reserva, sobre todo, a aquellos niños que asisten a una escuela laica donde no está presente la enseñanza del catecismo. En estos casos, la catequesis parroquial es considerada como "absolutamente imprescindible para la formación religiosa".

La catequesis escolar es catequesis eclesial porque es la Iglesia la que pone las normas que deben regir y es la Iglesia la que confiere la misión de enseñar. El derecho de la presencia de la catequesis en la escuela viene por la legislación que dimana del Concordato ${ }^{10}$. Ante un posible conflicto se propone que lo mejor será "hacer de la catequesis escolar la catequesis parroquial, coordinando y fusionando en una acción catequística única los esfuerzos del sacerdote y los del maestro" ${ }^{11}$. A la catequesis se le asignan estas finalidades: enseñar un contenido doctrinal y cultivar la fe; hacer vivir plena y consecuentemente la vida de la Iglesia; formar el espíritu de los catequizandos y su conciencia ${ }^{12}$.

J. M. Pedrosa dice que los catequistas del comienzo del siglo XX hasta mediados, con el P. Manjón y Daniel Llorente, enmarcan la catequesis en las

J.M., La acción catequética en la pastoral general de la Iglesia, en COLECTIVo, Por una formación religiosa para nuestro tiempo, Marova, Madrid 1967,30: "La guerra civil interrumpió de algún modo el esfuerzo catequético de España. /. . ./. Hemos confiado demasiado en nuestras circunstancias institucionalmente favorables para la formación de los cristianos. Nos hemos apoyado demasiado en un estamento profesional /.../. Ellos (los maestros) han tomado a sus espaldas la carga de catequizar a los españoles, sobre todo los de las masas populares. La postguerra española creo que ha significado un cierto periodo de, si no abandono, por lo menos, menos preocupación operante del clero diocesano, del clero parroquial, por la acción catequética".

${ }^{9}$ Mencía, G., art. cit., p. 191.

${ }^{10}$ MencíA, B., art. cit., p. 204- 205.

${ }^{11}$ IBíDEM, p. 210. En esta línea conviene también citar el libro de NiCENT J., Misión del catequista en la Iglesia, Colec. "Catequética” n. 2, 'La Salle', Madrid 1962; es una circular del Superior de La Salle a su Instituto Religioso que es traducida y difundida en España. El prólogo es de Daniel Llorente. El maestro es llamado catequista y la escuela tiene sentido porque en ella se hace catequesis o porque toda ella es catequesis. Es cierto que para poner a estos autores mencionados en contexto, conviene señalar que ambos son religiosos y que pertenecen a congregaciones dedicadas a la enseñanza. Pero no es menos cierto que es un pensamiento que va más allá de ser solo patrimonio de las congregaciones de enseñanza. Es un poco el ideal al que conviene apuntar. Morcillo, C., Circular, en "Boletín nacional de información catequística" 7 (1961) 7-8. En esta circular del entonces arzobispo de Zaragoza se dice que el modelo de "catecismo" es la escuela: "Siguiendo lo que manda la Santa Sede, los catecismos han de funcionar a manera de escuela".

${ }^{12}$ Garmendia, A., Finalidad de la catequesis, en "Boletín de orientación catequística" 19 (1963) 127-128; 20 (1963) 165-166; 21(1964) 207-208; 22 (1964) 259-260. 
coordenadas de educación que existen en España: la educación es entendida como un desarrollo de las potencialidades que Dios ha entregado a cada hombre ${ }^{13}$. La catequesis no va en disonancia con el resto del hacer escolar en este momento. La Iglesia de España no recorre el camino de renovación catequística de Europa. Se queda aislada, encerrada en una concepción de iglesia de cristianad.

Cuando llegue el documento de La enseñanza religiosa escolar (1979) todo este cimiento en el que se ha soportado la catequesis española caerá al suelo en dos de sus grandes facetas: el lugar de la catequesis, la escuela, y el agente de la catequesis, el maestro-catequista.

\section{La preocupación por la renovación de los métodos}

Progresiva e inexorablemente va apareciendo la necesidad de renovación de los métodos de formación religiosa. Hay ventanas por las que se van filtrando las ideas: apertura a lo que está pasando en la catequesis europea y, más influyente aún, lo que pasa en la escuela a niveles pedagógicos: las corrientes de renovación. Se impone una mentalidad de pedagogía religiosa cada vez más exigente ${ }^{14}$.

La exposición abstracta de los temas religiosos, sociales e históricos, sin conexión suficiente con la realidad humana, son considerados como los principales fallos de la enseñanza religiosa ${ }^{15}$. Los esfuerzos de renovación irán encaminados hacia una mayor consideración y cercanía del sujeto ${ }^{16}$. Es importante, al mismo tiempo, escuchar otro acento que apunta Salvador

${ }^{13}$ Pedrosa, V., Ochenta años de catequesis en la Iglesia de España, en "Actualidad catequética” 100 (1980) p. 628. EsTEPA, J.M., Dix années de travail catéchétique dans le monde. Au service de la formation religieuse de l'enfance, Fleurus, Paris 1960, 339-356. En este trabajo, el autor indica que en España no se ha seguido el ritmo de renovación que Europa sí hizo: una renovación pedagógica y metodológica, y, en segundo lugar, una renovación de los problemas catequísticos dentro de la pastoral eclesial.

${ }^{14}$ YANES, E., El movimiento catequético en España hoy, en "Actualidad Catequética" 48 (1970) 4-5.

${ }^{15}$ Herrera, J., Hacia una formación catequística, en "Boletín de orientación catequística" 25 (1964) 340.

${ }^{16}$ Estepa, J.M., Al encuentro de la vida. Manual de enseñanza catequética, Marova, Madrid 1964,7-15. J.M. Estepa estudió en el Instituto Católico de París, allí imparte algunos cursos, y es el introductor de las preocupaciones catequéticas que en dicho centro universitario se van fraguando con mucha repercusión en toda la Iglesia europea. 
Misser cuando destaca un defecto del catequista español: copia sin originalidad y sin pensamiento propio ${ }^{17}$.

La preocupación que comienza a prevalecer es la de la introducción de los métodos activos en la catequesis como instrumentos de vitalización ${ }^{18}$.

Un exponente interesante de esta época nos parece que es el libro de L. Maldonado que sirve de puente a dos corrientes, por una parte hace referencia a la catequesis kerigmática y, por otra, se sitúa en una apertura hacia una preocupación por el sujeto ${ }^{19}$. En este libro se afirma que la catequesis es una iniciación a las verdades de la fe y que el punto de arranque de toda enseñanza religiosa es el catecismo o que la raíz del problema de la mala formación religiosa no está tanto en el orden pedagógico cuanto teológico. Todos, como se puede observar, son principios de la catequesis kerigmática. El libro tiene una segunda parte pedagógica en que se hará referencia al "interés del sujeto" y es patente que la bibliografía empleada pertenece a la corriente francesa ${ }^{20}$ que ponía el énfasis cada vez más en la atención al sujeto.

\section{Una realidad compleja}

Como síntesis de este telón de fondo podemos resumir las ideas centrales en estos puntos:

- La Iglesia española del siglo XX (hasta el año 1970, de manera especial) vive una etapa pacífica sin preocupaciones catequéticas fuertes. Esta afirmación tiene que ser entendida también dentro de un contexto sociológico-político, el Régimen instaurado a partir de 1939.

${ }^{17}$ Misser, S., Catequizar, problema de renovación, Estela, Barcelona 1965. El libro recoge la experiencia de dos años de encargado de la catequesis y formación de catequistas de Barcelona. IDEM, La catequética hoy, en "Boletín de orientaci6n catequística" 17 (1963) 51.

${ }^{18}$ Febrero, $\mathrm{M}^{\mathrm{a}} \mathrm{A}$., Métodos catequísticos y métodos activos, en "Boletín de orientación catequística" 18 (1963) 90-93.

${ }^{19}$ Maldonado, L., Enseñanza religiosa y pedagogía de la fe, Editorial Verbo Divino, Estella (Navarra) 1963. En la presentaci6n se nos dice que se trata de un ensayo y no de una obra de investigación. Por eso tiene la característica de ofrecernos el ambiente que entonces vive la Iglesia española.

${ }^{20}$ Vemos que Luis Maldonado, en el libro anteriormente mencionado, cita a autores como Favreau, Sel de la terre, Paris 1961. Bournique, J., La pédagogie du héros (traduc. castellana, La pedagogía del héroe, Marova, Madrid 1964). El autor reconoce que ha sido ayudado por J.M. Estepa: "Las ideas eje de este libro, especialmente de la segunda parte se las debo a J.M. Estepa”, cfr., p. 10. 
- El lugar de la catequesis es la escuela, y no la comunidad cristiana. El agente de la catequesis o catequista es el maestro que posee una preparación pedagógica general para cumplir su misión. Esta preparación le capacita también para la catequesis escolar a través del instrumento conocido como catecismo.

- Junto al catequista-maestro va surgiendo la preocupación por el catequista "no maestro". El Hno. Juan José Medina Rodríguez, alma durante muchos años del Instituto de Catequética "San Pío X” de los Hermanos Lasalianos, escribía: "Pero el fenómeno más típico es sin duda el de los seglares. Es también el más inquietante. De tal modo se han resignado a la pasividad y les tienen sin cuidado estos problemas (de la misión de la Iglesia) que el considerarse ajenos y ver solo iglesia en el clero y en cuantos visten hábito talar es ya casi enfermedad endémica y, al parecer, incurable ${ }^{21}$ ". Estamos a las puertas de un problema importante: la formación de los catequistas. Elías Yanes decía: "La catequesis de un país es lo que sean sus catequis$\operatorname{tas}^{22}$ ". La formación de los educadores de la fe se venía haciendo en España de modo rutinario en la formación religiosa de las Escuelas de Magisterio. Era necesario abrir otras posibilidades: centro y escuelas de formación de catequistas ${ }^{23}$. Este problema sigue pendiente en la Iglesia de hoy.

- Otra cuña que irá removiendo el mundo de la catequesis, en un principio, es la preocupación pedagógica. Al estar la catequesis en la escuela será más visible la renovación pedagógica de otras materias y la necesidad de "hacer la catequesis" de acuerdo con los avances de las demás asignaturas.

- Pero no solo contará lo pedagógico, sino también lo sociológico ${ }^{24}: \mathrm{La}$ Ley de Educación (1970), el cambio político en España, la reflexión interna en el seno de la comunidad eclesial.

\footnotetext{
${ }^{21}$ Medina Rodríguez, J.J., Función de la catequesis en la totalidad de la misión de la Iglesia, en "Sínite" 2 (1960) 144.

${ }^{22}$ YANES, E., El movimiento catequético en España hoy, en "Actualidad Catequética" 48 (1970) 6-7.

${ }^{23}$ Domínguez, M., Escuelas parroquiales de formación de catequistas, "Boletín de orientación catequística" 16 (1963) 23-24.

${ }^{24}$ Ginel, Á., Una década crucial para la historia de la catequesis en España: los años 70, En "Sínite" 154-155 (2010) especialmente las páginas 413-420.
} 
- Finalmente hay que destacar la desazón interna dentro de la comunidad cristiana en el aspecto de la educación religiosa. Urge dar respuesta a una situación que se impone y que queda reflejada en el documento de La enseñanza religiosa escolar. Es un documento que señala dos realidades complementarias pero diversas: la enseñanza religiosa escolar (obligatoria para los centros escolares y libre para los alumnos), y la catequesis. El documento las presenta como complementarias y diversas. Visto desde hoy, puede parecer algo normal, porque es lo que vivimos. Pero en el momento histórico suponía una verdadera revolución. La escuela dejaba de ser "el lugar de la catequesis" y el maestro "el catequista" ordinario.

El mencionado documento sobre la enseñanza religiosa escolar recogía teóricamente una realidad que se estaba viviendo en la sociedad y en la Iglesia española al final de los años setenta, pero no cambiaba la mentalidad general de las personas ni de las comunidades cristianas. Había que elaborar una síntesis teórica de comprensión de la catequesis en la comunidad cristiana, del catequista, de los métodos propios de la pedagogía religiosa. Si bien es verdad que a nivel de Iglesia universal ya hay un reflexión sobre la catequesis ${ }^{25}$, la Iglesia española tendrá que hacer su propio camino de elaboración teórica y de implantación práctica. Es la originalidad y el reto que la reflexión catequética española irá afrontando ante el desenganche o la partición en dos de lo que era una única realidad de formación religiosa.

\footnotetext{
${ }^{25}$ Mencionamos las principales de referencia sobre el pensamiento catequético: Los documentos conciliares: Dei verbum (1965), Ad gentes (1965); SAGRADA CONGREGACIÓN DEL Clero, Directorio General de pastoral Catequética, Secretariado Nacional de Catequesis, Madrid 1973. La aprobación y publicación del documento es de 1971. SAGRADA CongREgACión del Culto Divino, Ritual de la Iniciación Cristiana de Adultos (RicA), Coeditores litúrgicos, Barcelona. La aprobación es del día 6 de enero de 1972. PABLo VI, Exhortación apostólica Evangelii nuntiandi (1975). Síntesis de los trabajos del Sínodo de los Obispos 1974 sobre La evangelización en el mundo contemporáneo. JUAN PABLO II, Exhortación apostólica Catechesi tradendae (1979). Síntesis del Sínodo de los Obispos de 1977 con el tema: La catequesis de nuestro tiempo. Esta Exhortación pasó por las manos de Pablo VI, Juan Pablo I y finalmente la publica Juan Pablo II.
} 
A. GINEL, SDB

\section{REDEFINICIÓN DE LA ESCUELA Y DE LA ESCUELA CATÓLICA}

Como hemos visto en el apartado anterior, la Iglesia española tiene que darse una nueva comprensión de la escuela y de la escuela cristiana al dejar de ser entendida la escuela pública como "lugar ordinario de catequesis". Es un largo trabajo de reflexión que tiene su punto referencial en el documento La enseñanza religiosa escolar (1979). Pero se trata de un problema que encontramos en la reflexión episcopal anterior, que se agudiza a partir de 1975, fecha de la muerte de Franco.

\section{La escuela, preocupación seria de la Iglesia antes del documento de 1979}

En la década de los sesenta, y especialmente en la década de los setenta, la sociedad española vive una convulsión educativa que culmina con la aparición de la Ley de Educación ${ }^{26}$. La Ley provoca una amplia consulta y participación de los diversos estamentos de la sociedad ${ }^{27}$. La Iglesia no está al margen de la realidad que vive la sociedad. Recogemos algunos aspectos de lo que la Iglesia reflexiona.

\subsection{La escuela en general}

La XXIII Asamblea Plenaria de la Conferencia Episcopal Española emite un Comunicado el 20 de diciembre de $1975^{28}$. Obsérvese la breve distancia de un mes justo de la muerte de Franco y el inicio de preocupaciones que ya el Episcopado palpa: un ambiente social nuevo en el que la Iglesia quiere permanecer fiel a su misión y fiel al pueblo que sirve: "La Iglesia de España quiere renovar su vida interna y su presencia en la vida del país ${ }^{29}$ ".

De cara a la sociedad, el Comunicado menciona explícitamente la enseñanza como un aspecto que urge dar solución ${ }^{30}$.

${ }^{26}$ Ley 14/1970, de 4 de agosto, General de Educación y Financiamiento de la Reforma Educativa. BOE» núm. 187, de 6 de agosto de 1970, páginas 12525 a 12546 (22 págs.)

${ }^{27}$ Leoncio VEGA GIL, La reforma educativa en España (1970-1990), http://www.scielo.br/scielo.php?script=sci_arttext\&pid=S0104-40601997000100008 Consultado 2019/06/05.

${ }^{28}$ La Iglesia ante el momento actual, en "Documentos colectivos del Episcopado español sobre formación religiosa y educación 1969-1980", Edice, Madrid 1981, pp. 367-372.

${ }^{29}$ Ibidem, p. 369.

${ }^{30}$ Ibidem, p. 370. 
En febrero de 1976, de nuevo, la XXIV Asamblea Plenaria de la Conferencia Episcopal aborda, de manera más precisa, el estudio de los problemas de la enseñanza ${ }^{31}$. Reconocen que hay un cambio en la sociedad española. El problema no es ya que la escuela sea lugar de catequesis, sino si en la escuela se deja espacio a la dimensión transcendente. No existe enseñanza neutra. "La apertura del hombre a lo transcendente es una dimensión constitutiva radical del ser humano. Por ello, una formación integral exige que se preste atención al universo religioso de la Persona ${ }^{32}$ ". La realidad que se vive supera al mismo hecho de la catequesis escolar. Se cuestiona hasta que "lo religioso" pueda tener lugar en la escuela.

Los obispos españoles argumentan y defienden la presencia de la religión en la escuela desde los derechos del alumno y de los padres, "derechos prevalentes sobre cualquiera otros ${ }^{33}$ ". Además, los bautizados tienen derecho a una educación cristiana. "El sentido cristiano de la existencia a que tiene derecho todo bautizado, exige la presencia de la Iglesia en el medio cultural que es la escuela, en tanto sea esta el cauce normal básico para la transmisión de la cultura ${ }^{34}$ ".

La conclusión es clara: para los obispos, la escuela es el lugar privilegiado para la transmisión de unos conocimientos orgánicos de la fe, y siempre relacionados con el resto de los saberes que en la escuela se imparten. El pluralismo de la sociedad hace que esta perspectiva educativa sea más necesaria. Un acontecimiento político de apertura a corrientes y visiones de la persona diversas hace reaccionar a la Iglesia sosteniendo que la escuela es el lugar donde se fragua el tipo de hombre a través de un tipo de educación.

- Todo lo que acontece en la escuela afecta al sentido último de la vida humana, y a la vida de fe.

- La Iglesia se siente legitimada a tener una palabra justamente para defender un sentido de persona abierta al transcendente.

- Se defiende un tipo de escuela que no arrincone la formación religiosa porque eso afectaría a la formación integral de la persona ya sea bautizada o no.

${ }^{31}$ Los planteamientos actuales de la enseñanza. Nota en el comunicado de la XXIV Asamblea Plenaria de la conferencia Episcopal Española, Madrid 28 de febrero de 1976, en "Documentos colectivos del Episcopado español sobre formación religiosa y educación 19691980", Edice, Madrid 1981, pp. 373-376.

${ }^{32}$ Ibidem, p. 383.

${ }^{33}$ Ibidem, p. 383.

${ }^{34}$ Ibidem, p. 385. 


\subsection{La escuela católica}

La escuela católica no se diferencia de la escuela estatal en cuanto a lo que le es propio: formación integral de la persona. La existencia de la escuela católica está amenazada porque toda la escuela en la etapa política anterior ha sido considerada como "escuela católica". Comienza ahora una diferenciación entre escuela y escuela católica.

La defensa de la escuela católica propiamente dicha se extrae de la Gravissimum educationis momentum ${ }^{35}$.

- La escuela católica es el exponente máximo de la presencia de la Iglesia en la educación.

- Es preciso reflexionar y adaptar la escuela católica al momento presente de la problemática social.

- La escuela católica es responsabilidad de toda la comunidad cristiana.

Se da por supuesto la formación religiosa en esta escuela católica. Los problemas vienen de la "actualización" de la escuela católica y de su supervivencia.

\subsection{La comunidad cristiana en el campo educativo}

La comunidad cristiana es la responsable de la acción pastoral de la Iglesia en el ámbito escolar.

La acción pastoral de la Iglesia se lleva a cabo a través de los educadores cristianos, de los profesores de religión y de los equipos de pastoral de los centros docentes, así como con la participación de los padres y alumnos cristianos en los órganos de gobierno.

\section{La enseñanza religiosa en las escuelas ${ }^{36}$}

Junto a la redefinición de escuela como lugar de formación integral se va repensando el mismo concepto de enseñanza religiosa. De entrada, hay que

${ }^{35}$ Declaración sobre la educación cristiana de la juventud (Gravissimun educationis momentum), (1965).

${ }^{36}$ La enseñanza religiosa en las escuelas. Declaración de la XXVI Asamblea Plenaria de la Conferencia Episcopal Española. Madrid 25 de junio de 1977, en "Documentos colectivos del Episcopado español sobre formación religiosa y educación 1969-1980”, Edice, Madrid 1981, 409-414. 
advertir un cambio de vocabulario. No se habla de catequesis escolar sino de enseñanza religiosa. Es fácil comprobar que si bien cae la expresión "catequesis escolar" parece que sigue planeando, de alguna manera, su contenido cuando se habla de "educación en la fe". Educación en la fe se usa mucho cuando se menciona la necesidad que los "bautizados" tienen de alimentar o incrementar las exigencias del bautismo ya sean las exigencias contraídas por los padres, como la propia responsabilidad personal de potenciar el bautismo recibido.

La reflexión de los obispos españoles es muy consciente de las corrientes de fondo que sacuden a la sociedad española del momento y quiere reedificarse sobre pilares sólidos: la libertad y los derechos humanos. En este marco, los Obispos ponen encima de la mesa su pensamiento sobre la educación en la fe.

- Se parte de un hecho básico: el bautismo que compromete a los padres a dar a sus hijos una educación en la fe ya sea por sí mismos o por otros educadores.

- Se mantiene como ámbitos de educación en la fe: la parroquia, la familia y la escuela.

- El proceso de educación en la fe es inseparable del proceso educativo general del hombre. De ahí que los padres sientan la necesidad de conseguir que la educación de sus hijos integre la formación moral y religiosa según la fe de la Iglesia.

- La fe no es un añadido a la cultura. La fe es una luz que se proyecta sobre todas las zonas del pensamiento y vivifica el desarrollo personal y comunitario.

- El sistema educativo debe impartir esta educación en la fe por respeto a las convicciones de los alumnos y de sus padres.

Se percibe, en este tiempo previo al documento eclesial de La enseñanza religiosa escolar, que marca una línea divisoria entre lo que es catequesis y enseñanza religiosa, un contexto social que combate la presencia de la religión en la escuela. La Iglesia se emplea a fondo para mantener abierta la puerta de su presencia en la escuela. Hay matices que van apareciendo en el significado que hay detrás de "la religión en la escuela".

Además, la Iglesia se sabe garante de la religión en la escuela. Pide al Estado que "la enseñanza de la religión católica se imparta en conformidad con la doctrina de la Iglesia, reconociendo la competencia que corresponde a la Iglesia sobre la misma; enseñanza de la religión debe ser hecha con una intencionalidad educativa, respetuosa de la libertad y del proceso de 
maduración del alumno, pero sin reducirla a una mera información descriptiva del fenómeno religioso ${ }^{37}$ ".

Creo que es importante este itinerario de progresiva formación de conceptos como escuela, enseñanza religiosa, educación en la fe, competencia de la Iglesia en esta materia, intencionalidad educativa que supera la pura información descriptiva de un fenómeno religioso. La libertad y el proceso de maduración del alumno van íntimamente unidos a la presencia de la religión en la escuela.

\section{EL PUNTO DE LLEGADA: ENSEÑANZA RELIGIOSA EN LA ESCUELA}

Hay que subrayar que en el periodo ${ }^{38}$ de diez años la Iglesia española tiene que adaptarse a todo lo que está pasado en su seno ${ }^{39}$. La respuesta se elabora mirando los documentos conciliares. Un estudio más detallado y amplio del problema de la religión en la escuela en España pondría de manifiesto los vaivenes entre los acontecimientos sociopolíticos de la sociedad, y la reflexión teórica y práctica de la Iglesia.

Los ejes nucleares los podemos resumir de esta manera: la Iglesia es consciente de que tiene que ser fiel a su tarea educativa hoy como lo fue a lo largo de la historia. La Iglesia española es consciente de que no se puede sostener por más tiempo la presencia en la escuela nacida a partir del Ré-

${ }^{37}$ Ibidem, La enseñanza religiosa en las escuelas, p. 412.

${ }^{38}$ Este periodo va de 1969 a 1979. En 1969: COMISIÓN EPISCOPAL DE ENSEÑANZA Y EDUCACión Religiosa, La Iglesia y la educación en España hoy, en "Documentos colectivos del Episcopado Español sobre la formación religiosa y educación. 1869-1980", Edice, Madrid 1981, pp. 21-114. Este documento, de suma importancia, pone a la Iglesia española en una reflexión conciliar sobre la educación. Salir del adormecimiento y acoger la situación de la sociedad española en pleno cambio y sitúa el momento de reflexión eclesial sobre los temas de educación y de educación religiosa que culminarán con la maduración realizada durante la década convulsa de los setenta en el documento La enseñanza religiosa escolar.

${ }^{39}$ Señalo solo cuatro acontecimientos de hondo calado: 20 de noviembre de 1975, muerte de Franco; 31 de enero de 1976, Alternativa de la enseñanza, difundida por el Colegio de Licenciados de Madrid y que recogía ideas, propuestas y principios de enseñanza progresistas que se fueron fraguando a partir de 1970, cfr. http://www.educacionyfp.gob.es/dam/jcr:ce2b27d8-15b8-43eb-b565-5b51ca11edcf/re199218-pdf.pdf (consultado 26 de junio de 2019); nueva Constitución española, 1978; 3 de enero de 1979, Acuerdo Santa Sede - Gobierno Español que sustituye al Concordato de 1953. 
gimen de 1936; esto le lleva a defender su presencia en la escuela española a través de la enseñanza religiosa entendida como "derecho de la persona a sus creencias religiosas". La firmeza con la que la Iglesia mantiene esta postura le lleva a entablar, como más adelante veremos, una diferenciación entre enseñanza religiosa y catequesis, si bien se percibe que, siempre que se pueda, la enseñanza religiosa debería tomar un tinte más catequético.

Otro acento que hay que reseñar es que el documento de La enseñanza religiosa escolar es la culminación de una reflexión que se va fraguando a partir de las corrientes de pensamiento sobre la escuela que la sociedad española vive.

El documento mencionado no presenta novedades grandes con el inmediato tiempo precedente. Sí se alza como punto de maduración y de referencia para toda la acción pastoral de la Iglesia en la escuela y en la comunidad cristiana en adelante.

Nuestra reflexión a partir de ahora sigue de cerca el contenido de $L a$ enseñanza religiosa en la escuela ${ }^{40}$.

\section{Punto de partida: función de la escuela en la sociedad}

La enseñanza religiosa escolar, como el mismo documento reconoce (cfr. n. 1) ocupa un lugar destacado en la preocupación de la Iglesia en el momento de su aparición. Está en juego la presencia de la Iglesia en el espacio educativo primordial: la escuela. La Iglesia se ve ante la espada y la pared. Con urgencia tiene que elaborar una propuesta razonada para seguir presente en la escuela. A la pregunta inicial ¿por qué la enseñanza religiosa escolar? se responde dando una visión, desde la fe, de la función propia de la escuela en la que quepa, no por privilegio, sino por naturaleza misma de la escuela, la enseñanza religiosa y con ella la presencia eclesial.

La escuela es concebida como el ámbito en el que "no solo se adquiere información científica y hábitos intelectuales según los distintos campos del saber, sino también se aprende a orientarse en su vida individual y social" (n. 10).

El sistema educativo en general es entendido como factor de humanización y "la formación religiosa es exigencia imprescindible porque funda,

${ }^{40}$ COMISIÓn EPISCOPAL de ENSEÑANZA y CATEQUesis, Orientaciones pastorales sobre la enseñanza religiosa escolar. Su legitimidad, carácter propio y contenido, en "Documentos colectivos del Episcopado Español sobre la formación religiosa y educación. 1869-1980”, Edice, Madrid 1981, pp. 543-589. El documento está fechado el día 11 de junio de 1979. 
potencia, desarrolla y completa la acción educadora de la escuela” (n. 12). Situada la función de la escuela en la formación integral de la persona, se distancia de la argumentación de que la presencia de la Iglesia en la escuela dependa de la confesionalidad del Estado (n. 23).

No se quiere caer en la tentación de que la Iglesia se recluya en las propias instituciones. La Iglesia reclama la escuela como foro de diálogo entre la fe cristiana y el saber humano con la finalidad de ayudar a la persona del alumno a situarse lúcidamente ante la tradición cultural, a insertarse críticamente en la sociedad, a dar respuestas al sentido último de la vida.

Dos ideas fuerza parecen subyacer a toda la argumentación:

a) El sentido de la misión de la Iglesia en la sociedad, que tiene en las constituciones conciliares Lumen Gentium y Gaudium et Spes, un respaldo teológico sin miedos ni complejos al diálogo entre fe y cultura.

b) La antropología cristiana de la formación integral de la persona, que siempre apunta a la apertura al trascendente, y, en los bautizados, al cultivo de su maduración en la fe.

c) El derecho de los padres a la elección (no imposición) de una enseñanza para sus hijos que incluya la dimensión religiosa.

Con estos principios la Iglesia de España defiende y mantiene su derecho a estar presente en la escuela.

\section{Los imperativos de la escuela a la enseñanza religiosa}

Defendida la presencia de la enseñanza religiosa en la escuela por su originalidad específica de preocuparse por las cuestiones del sentido de la vida, por el derecho de los padres que lo deseen para sus hijos, el documento que analizamos describe las características que debe tener la religión en la escuela. Su presencia en la escuela, ámbito propio de la sociedad para dar a los ciudadanos un grado de cultura conveniente, impone a la enseñanza religiosa condiciones o modalidades de cómo debe desarrollarse, acomodarse y conducirse con el entorno de las demás materias escolares.

La reflexión obligada que la Iglesia realiza sobre la enseñanza religiosa escolar, vista desde hoy, supone una ruptura con el pasado de la catequesis escolar y será el inicio de una reflexión sobre la catequesis que no cesa de reinterpretarse. Por eso, creo que es una etapa de final de una sociedad de cristiandad y el comienzo de una reflexión intraeclesial muy importante. 


\subsection{Carácter escolar de la enseñanza religiosa}

Los Obispos precisan y aceptan la originalidad de la realidad escolar. He aquí algunas consecuencias que no son pequeñas si se comparan con la etapa precedente.

- En la escuela la Iglesia "presta un servicio" (n. 61). No es una institución eclesial. Se tiene que adaptar a ella, y no a la inversa. El Estado es el responsable último de garantizar la calidad de la enseñanza y la efectividad de este servicio a todo tipo de escuela: pública y privada.

- El adjetivo "escolar" exige que la enseñanza religiosa adopte "rigor escolar y estatuto académico" (n. 51.52) como toda disciplina; que se "adapte a los objetivos y métodos propios del quehacer escolar y encarnar su acción dentro de los condicionantes concretos históricos de la institución docente" (n. 61). Esto se traduce en que el ámbito escolar no es ámbito catequético: no hay que proponer en la clase de religión "todas las dimensiones de la catequesis: la plena iniciación en la experiencia cristiana, en el compromiso de la fe, en la integración en la comunidad eclesial" (n. 50). Estas matizaciones obligan a delimitar bien lo que es catequesis y lo que es enseñanza religiosa. En la práctica, no dejarán de suscitar continuamente interrogantes concretos e interrogantes de fondo sobre la presentación de los contenidos religiosos. La persona del profesor contribuirá mucho a resolver los interrogantes o a interrogarse más ante una clase de religión reducida a cultura religiosa.

- El objetivo de la enseñanza escolar es integrar la dimensión religiosa en la formación de la personalidad y proporcionar un conocimiento de la fe que estimule el diálogo interdisciplinar (n. 65). "El pensamiento cristiano no puede dispensarse de una confrontación con los humanismos e ideologías contemporáneas" (n. 36).

\subsection{Control eclesial del qué y de quiénes}

La enseñanza religiosa es entendida como "servicio eclesial ${ }^{41}$ " porque la Iglesia está llamada a servir a los hombres. Desde esta perspectiva señalamos solo dos elementos que son importantes:

${ }^{41}$ Véase el punto 4 de la primera parte titulado La enseñanza religiosa, servicio eclesial (n.42-57) del documento que analizamos. 
- Los destinatarios de la enseñanza religiosa, en principio, no obligatoriamente, son "toda clase de alumnos" (n. 46) porque a todos está dirigida la acción de la Iglesia, y a todos puede ayudar la enseñanza religiosa a pensar y a actuar el sentido de la vida. La religión se propone pero no se impone.

- El contenido y las líneas metodológicas fundamentales de él derivadas, "deben ser decididos por la competente autoridad eclesiástica" (n. 43). La presencia de la Iglesia en la escuela es una evangelización muy particular y, si es evangelización, es confesión, es exposición de un patrimonio de fe que no cambia porque el lugar donde se presente sea la escuela.

- De aquí se sigue, con lógica coherente, que quienes imparten la enseñanza religiosa estén ligados a la Iglesia, realicen su tarea con actitud confesante y según los contenidos y los métodos garantizados por la Iglesia (n. 51). Queda así desautorizada toda interpretación de reducir la enseñanza religiosa a solo saber: "La afirmación de que quien debe impartir esta cultura (religiosa) es simplemente "quien la posea", de cuya competencia profesional se haga cargo la sociedad e instancias civiles, sin que implique necesidad alguna de una vinculación confesante con la Iglesia, cuya fe se enseña /... La instancia civil no es competente para otorgar esta garantía" (n. 55).

\section{EL PUNTO DE PARTIDA: LA ORIGINALIDAD DE LA CATEQUESIS}

La reflexión eclesial sobre la originalidad de la enseñanza religiosa escolar, tal como acabamos de ver, supone un "punto de llegada". En ese mismo momento, se abre una reflexión no menos importante sobre la catequesis. Entendemos que realmente se inicia con seriedad una tarea ardua de comprensión del término catequesis en la Iglesia española. En esta geografía concreta, la profundización se hace con connotaciones sociales muy específicas cuyo punto de referencia es el documento de La enseñanza religiosa escolar. Aclarada la naturaleza de la enseñanza religiosa, por la urgencia del diálogo necesario entre la Iglesia y el Estado, se va madurando progresivamente el concepto de catequesis que tendrá un desarrollo más exhaustivo en el documento La catequesis en la comunidad cristiana ${ }^{42}$ (1983).

${ }^{42}$ Comisión Episcopal de Enseñanza y CATEQuesis, La catequesis de la comunidad. Orientaciones pastorales para la catequesis en España, hoy, Colección "Documentos catequéticos, n. 1", Edice, Madrid 1983. 
Redefinir cómo se tiene que entender la catequesis coincide en el tiempo con la búsqueda de sentido de la catequesis que ocupa a la Iglesia universal.

\section{EI marco de la reflexión sobre la catequesis en la Iglesia universal: los Sínodos}

La Iglesia universal, durante la década de los setenta, continúa un movimiento de reflexión de la catequesis para poner de relieve su importancia en el conjunto de la acción pastoral. De la misma manera que en la Iglesia preconciliar hubo movimientos llamados "litúrgico", "movimiento bíblico" y otros, también existió un movimiento catequético ${ }^{43}$. Nosotros nos centramos en lo que pasa en la Iglesia universal justo en los días en que la Iglesia española rehace y elabora su "teoría sobre la catequesis".

En los setenta, la Iglesia universal vive la realidad de dos sínodos dedicados a la reflexión sobre la evangelización y la catequesis. Hay una razón que demanda estos Sínodos: "En todos los países, cualquiera que sea su sistema social, o su tradición cultural, hay hombres y mujeres que buscan, luchan y trabajan por el bien común y por construir un mundo nuevo. Los viejos sistemas de valores con frecuencia no se aceptan ya y hasta se derrumban; las seguridades humanas se ven amenazadas por la violencia, la opresión y el desprecio de la persona. Algunos llegan a experimentar que las esperanzas puestas en las ideologías y en la técnica son insuficientes" ${ }^{44}$. Algo está cambiando tan rápidamente como Gaudium et spes señaló con acierto: "El género humano se haya hoy en un periodo nuevo de su historia caracterizado por cambios profundos y acelerados, que progresivamente se extienden al universo entero. Los provoca el hombre con su inteligencia y su actividad creadora: pero recaen luego sobre el hombre... se puede hablar de una verdadera metamorfosis social y cultural que redunda también sobre la vida religiosa" (n. 4).

Hacemos un breve repaso de esta "efervescencia" que se produce a los diez años del finalizado el Concilio Vaticano II.

${ }^{43}$ Elías YANES, Movimiento catequético español, en "Nuevo Diccionario Catequético", San Pablo, Madrid 1999, p. 1570-1587. José MonTero, Movimiento catequético español preconciliar, en "Diccionario de Catequética", Editorial CCS, Madrid 1987, p. 582-584. Ubaldo Gianetto, Movimiento catequético, en "Diccionario de Catequética", Editorial CCS, Madrid 1987, p. 581-582.

${ }^{44}$ Mensaje del Sínodo de los Obispos 1977, n. 2. Cfr. https://www.cenacat.org/uploads/mensaje_del_snodo_para_la_catequesis_-_1977.pdf 


\subsection{4: Sínodo de los Obispos sobre la "Evangelización en el mundo con- temporáneo"}

El fruto precioso de este sínodo fue la Exhortación Apostólica firmada por Pablo VI, Evangelii nuntiandi $i^{45}$ (en adelante EN) considerada por muchos estudiosos como uno de los documentos postconciliares más relevante tanto por su forma como por su fondo. Pablo VI convoca el Sínodo ante el "secularismo ateo" y la "descristianización" como dos grandes desafíos a la acción de la Iglesia.

$E N$ proporciona a la catequesis un marco de referencia: la evangelización (EN 17-24). El término evangelización es amplio y se irá perfilando poco a poco. Ya se habla de primer anuncio ( $E N 51-52)$, de una acción que precede a la catequesis.

\subsection{7: Sínodo de los Obispos sobre "La catequesis en nuestro tiempo"}

Este Sínodo, en principio continuación del anterior, regaló a la Iglesia un primer texto: Mensaje al pueblo de Dios ${ }^{46}$, que orientó la naturaleza de la catequesis como manifestación de la salvación de Dios que tiene una original pedagogía de la fe; además, el Mensaje puso a la comunidad cristiana como "lugar o ámbito de la catequesis". La comunidad cristiana pone en el centro de la educación en la fe a la comunidad cristiana, aunque se siga hablando de los lugares tradiciones de educación en la fe (familia, parroquia, escuela). Añade un nuevo lugar: las pequeñas comunidades eclesiales, asociaciones y grupos juveniles y otras.

La muerte de Pablo VI y la de su sucesor, Juan Pablo I, demoraron el documento final del Sínodo que apareció en 1979. Fue Juan Pablo II quien publicó Catechesi tradendae ${ }^{47}(C T)$ después de haber pasado por las manos de los dos papas anteriores.

Esta Exhortación Apostólica sitúa la catequesis en la actividad pastoral y misionera de la Iglesia ${ }^{48}$. No se confunde la catequesis con la evange-

${ }^{45} \mathrm{http}: / /$ w2.vatican.va/content/paul-vi/es/apost_exhortations/documents/hf_p-vi_exh_19751208_evangelii-nuntiandi.html

${ }^{46} \mathrm{http}: / /$ www.vatican.va/roman_curia/synod/documents/rc_synod_doc_20081024_message-synod_sp.html

${ }^{47}$ http://w2.vatican.va/content/john-paul-ii/es/apost_exhortations/documents/hf_jpii_exh_16101979_catechesi-tradendae.html

${ }^{48}$ Cfr. Números 18-25. 
lización. Tiene originalidad y es complementaria con otras actividades eclesiales. "La finalidad de la catequesis, en el conjunto de la evangelización, es la de ser un período de enseñanza y de madurez, es decir, el tiempo en que el cristiano, habiendo aceptado por la fe la persona de Jesucristo como el solo Señor y habiéndole prestado una adhesión global con la sincera conversión del corazón, se esfuerza por conocer mejor a ese Jesús en cuyas manos se ha puesto: conocer su «misterio», el Reino de Dios que anuncia, las exigencias y las promesas contenidas en su mensaje evangélico, los senderos que Él ha trazado a quien quiera seguirle" $"$.

En resumen, toda la Iglesia vive la necesidad de una nueva comprensión del concepto de catequesis, de sus métodos y del lenguaje, sin que se ponga en peligro la integridad del contenido de la fe. Hay un subterráneo y fuerte miedo a "rebajas" en la proposición del Mensaje del Evangelio ya sea por quedarnos en los medios que se utilizan o en un anuncio que considere tanto a la persona que no se proponga la verdad de Cristo con integridad. Por otra parte, se siente la necesidad de acoger las novedades pedagógicas y de acoger a las personas en sus culturas concretas, en sus problemas. Todo ello obliga a salir de la repetición rutinaria, del letargo, de la improvisación irreflexiva que engendra desconcierto.

\section{La respuesta de la Iglesia española}

El documento La enseñanza religiosa escolar pone, sin desarrollar, unas bases de diferenciación entre catequesis y enseñanza religiosa ${ }^{50}$ :

\begin{tabular}{|l|l|l|}
\hline \multicolumn{1}{|c|}{ Enseñanza religiosa escolar } & \multicolumn{1}{c|}{ Catequesis } \\
\hline ÁMBITOS & Escuela & Comunidad cristiana \\
\hline INICIATIVA & $\begin{array}{l}\text { Servicio de la Iglesia en un ámbito } \\
\text { que no le es propio. }\end{array}$ & $\begin{array}{l}\text { Iniciativa propia en unas es- } \\
\text { tructuras que la Iglesia crea } \\
\text { para catequizar. }\end{array}$ \\
\hline $\begin{array}{l}\text { DESTINATA- } \\
\text { RIOS }\end{array}$ & $\begin{array}{l}\text { Iniciativa de los padres que piden } \\
\text { que lo religioso se integre en la } \\
\text { formación humana (sentido de la } \\
\text { vida, del mundo desde la perspec- } \\
\text { tiva cristiana). }\end{array}$ & $\begin{array}{l}\text { La persona (niño/a, adoles- } \\
\text { cente, joven, adulto) acude por } \\
\text { la fe e integración en la comu- } \\
\text { nidad. }\end{array}$ \\
\hline
\end{tabular}

\footnotetext{
${ }^{49}$ Cfr. n. 20.

${ }^{50} \mathrm{Cfr}$. La enseñanza religiosa escolar, nn. 58-70.
} 


\begin{tabular}{|l|l|l|}
\hline OBJETIVOS & $\begin{array}{l}\text { Estimular, por el conocimiento de } \\
\text { la fe, el diálogo entre Evangelio y } \\
\text { cultura. }\end{array}$ & $\begin{array}{l}\text { Estimular, por el conocimiento } \\
\text { de la fe, el diálogo entre Evan- } \\
\text { gelio y cultura. Que la fe del } \\
\text { cristiano se inicie y madure en } \\
\text { el seno de la comunidad... La } \\
\text { vivencia de la comunidad cris- } \\
\text { tiana es el lugar apropiado } \\
\text { para la maduración de la fe } \\
\text { personal y comunitaria. }\end{array}$ \\
\hline COMPLEMEN- & $\begin{array}{l}\text { Una buena enseñanza religiosa } \\
\text { creará el deseo de una plena cate- } \\
\text { quización en la comunidad. } \\
\text { Pasar de la enseñanza religiosa de } \\
\text { calidad a la catequesis es conside- } \\
\text { rado como el caso más frecuente. }\end{array}$ & $\begin{array}{l}\text { Una catequesis viva es el te- } \\
\text { rreno más apropiado para que } \\
\text { fructifique la enseñanza reli- } \\
\text { giosa. } \\
\text { Cuando el grupo de alumnos } \\
\text { es mayoritariamente creyen- } \\
\text { te... la enseñanza religiosa } \\
\text { podrá alcanzar objetivos pro- } \\
\text { pios de la catequesis. }\end{array}$ \\
\hline
\end{tabular}

Como se puede ver, hay una "inclinación" a potenciar el modelo de catequesis como si fuera una referencia a la que apuntar también desde el horizonte de la enseñanza religiosa, "cuando se den las condiciones" para ello.

\section{Notas del carácter propio de la catequesis}

La catequesis de la comunidad (CC) es una reflexión estrictamente eclesial. Es cierto que hay unas razones externas a la Iglesia que la provocan y retan. Pero es la Iglesia la que siente la necesidad de discernir la catequesis no solo en España, pero aquí nos limitamos a la reflexión de la Iglesia española.

\subsection{Dónde situar la catequesis en la Iglesia}

La catequesis de la comunidad comienza situando la catequesis en la misión de la Iglesia. Se advierte que la reflexión sigue de cerca las enseñanzas de Catechesi tradendae. La lógica es muy clara:

- Jesús anuncia que el reinado de Dios está cerca $(M c 1,15)$ y es constituido Señor: "Dios ha constituido Señor y Mesías al mismo Jesús a quien vosotros crucificasteis" (Hech 2,36). 
- La Iglesia continúa esta misión de Jesús mediante la proclamación del Evangelio, el testimonio de la vida y la acción liberadora de los cristianos. Evangelizar significa para la Iglesia llevar la buena nueva a todos los ambientes de la humanidad y, con su influjo, transformar desde dentro, renovar la misma humanidad ( $C C$ n. 16).

- La catequesis tiene un papel esencial dentro de esta misión evangelizadora de la Iglesia ( $C C$ n. 22).

- En el proceso de evangelización, la catequesis es: un momento (CC n. 30), un elemento ( $C C$ n. 31) del proceso de evangelización que se articula pero no se confunde con otros elementos. Así, la catequesis es precedida por la acción misionera o primer anuncio que prepara los cimientos de la persona para su integración en la comunidad y hay otros elementos que emanan y sigue a la catequesis (los sacramentos, la vida de la comunidad) ( $C C$ n. 33). En resumen, la catequesis no es toda la acción evangelizadora. Ninguna Iglesia particular o comunidad cristiana local podrá decir que evangeliza porque hace catequesis, sino que, porque evangeliza, también, entre otras cosas, hace catequesis.

- La catequesis da continuidad a la acción evangelizadora primera y sin ella no habría raíces fuertes de cristianos consistentes, no habría Iglesia ( $C C$ n. 35).

- Se define la catequesis como "ese periodo intensivo y suficientemente prolongado en el que se capacita básicamente a los que han dado su adhesión al evangelio, para entender, celebrar y vivir la buena nueva del Reino. La catequesis es como el noviciado de los cristianos, el periodo de maduración de la conversión inicial, la etapa en la que los convertidos se inician en todos los aspectos de la vida de la comunidad para poder integrarse en ella de una manera adulta, como sujetos activos de la misma" ( $C C$ n. 46).

Conviene resaltar el esfuerzo de dar originalidad a la catequesis no solo desde su función noética o de instrucción, sino que adquiere una amplitud de facetas que no se dan en lo que hemos visto de la enseñanza religiosa.

Cuando se habla de "noviciado" se cita el documento conciliar Ad gentes (n. 14) que describe el catecumenado de esta manera: "Los que han recibido de la Iglesia la fe en Cristo, sean admitidos con ceremonias religiosas al catecumenado que no es una mera exposición de dogmas y preceptos, 
sino una formación y noviciado convenientemente prolongado de la vida cristiana, en que los discípulos se unen con Cristo, su Maestro". Es importante que se tome esta cita aquí sin hablar expresamente de catecumenado. Estamos en los primeros momentos de la reflexión de la naturaleza de la catequesis. El mismo documento $C C$, más adelante, ya menciona la dimensión catecumenal de la catequesis. Pero aquí tenemos los indicios. Asistimos a los primeros pasos de comprensión de la catequesis acudiendo al catecumenado de la Iglesia de los primeros siglos. De ahora en adelante, el catecumenado primitivo será referencia obligada para definir y entender la catequesis.

En resumen, La catequesis de la comunidad construye su originalidad en la más pura tradición eclesial de la mano del Concilio Vaticano II en su Decreto sobre la Actividad misionera de la Iglesia (Ad gentes). Se sale de una reflexión emanada de la lógica de la iglesia de cristiandad, de la naturaleza de la escuela y se sitúa en otra órbita: lo que la Iglesia hizo y hace en su acción misionera, allí donde no hay una tradición cristiana y se tiene que implantar como novedad sin tradición cristiana previa.

\subsection{Naturaleza o carácter propio de la catequesis}

Situada la catequesis en el maraco amplio de la misión de la Iglesia, la evangelización, como momento que sigue al primer anuncio del Mensaje, el documento La catequesis de la comunidad hace el esfuerzo de responder a la pregunta: ¿Qué es la catequesis? ¿Cuáles son los elementos constitutivos que la diferencian de otras acciones eclesiales?

Lo primero que llama la atención es que el documento se ve obligado a admitir dos tipos de catequesis, uno restringido y otro amplio. Este aparente detalle es el mejor indicativo de una "situación de tránsito" o "etapa de reelaboración" de una teoría sobre la catequesis que tiene en cuenta lo que se venía haciendo y la apertura al futuro.

- "La catequesis en sentido restringido es la enseñanza elemental de la $f e$ ( $C C$ n. 79). El término "enseñanza elemental" conecta con una tradición que nosotros hemos denominado "catequesis escolar-el catecismo en la escuela". Más adelante se precisa que este sentido de catequesis "no basta" ( $C C$ n. 80).

- "La catequesis en sentido pleno es la iniciación cristiana integral no solo en la doctrina, sino también en la vida y el culto de la Iglesia así como su misión en el mundo" (CC n. 79). Es lo que la Iglesia primi- 
tiva hace cuando no disponía de espacio en otros ámbitos de la sociedad. La comunidad cristiana era el único y verdadero espacio para engendrar nuevos hijos. La comunidad cristiana se siente fecunda en sí misma. Es la dimensión que en los setenta tiene que redescubrir la comunidad, después de haber estado mucho tiempo en otro lugar menos propio.

La catequesis de la comunidad, en sintonía con Catechesi tradendae, se aparta de una catequesis en la escuela, válida en una sociedad de cristiandad, y hunde la reflexión en la iniciación cristiana del catecumenado de la Iglesia de los primeros siglos.

Si antes hemos dicho que se aludía al catecumenado sin nombrarlo, al determinar lo constitutivo de la catequesis, se habla muy explícitamente de una catequesis de inspiración catecumenal (CC n. 83). Las tareas que constituyen la dimensión catecumenal son:

- Iniciación orgánica en el conocimiento del misterio de Cristo y el designio salvador de Dios. Es un conocimiento de la fe, por tanto, incluye nociones, valores, experiencias, acontecimientos... La vida de fe no es solo un suspiro del alma. El conocimiento es elemento fundamental y director de todo el proceso (Cfr. CC n. 85-87).

Es de notar cómo $C C$, al describir las tareas de la catequesis "'cae en la tentación" de añadir concreciones del momento histórico que entendemos como algo que nos revela las diversas sensibilidades existentes en la Iglesia. Así, por ejemplo, cuando se describe el concepto de iniciación orgánica en el conocimiento de la fe, se precisa que es una tarea que deja mucho que desear "entre nosotros" (= Iglesia en España) y especifica la "pobreza doctrinal de muchas catequesis con jóvenes y adultos" ( $C C$ n. 86). Se percibe una sobrecarga de lo vivencial en detrimento de lo que es un auténtico saber.

- Iniciación en el estilo de vida nuevo, es decir, en las actitudes específicamente cristianas, todo aquello que se desprende de las exigencias evangélicas (Cfr. CC n. 87-88). Pasar del solo saber a hacerlo vida personal, asumida, práctica y cotidiana, es decir, "un saber aplicado en la vida". Se reconoce lo duro y lento de este proceso de construcción del "hombre nuevo" tanto que se afirma: "Esta es seguramente la principal razón de que todo proceso catequético haya de ser un periodo suficientemente prolongado de formación y noviciado de la vida cristiana" (CC n. 88). 
- Iniciación en la vida de oración y en la vida litúrgica (Cfr. CC n. 8990). El creyente es un dialogante con Dios, oración, y un celebrante de los misterios de salvación. Lo que ha hecho Dios por nosotros lleva a la persona a la oración y la celebración. La catequesis se intelectualiza si no lleva a estas dimensiones prácticas de relación con Dios y de relación del pueblo de Dios que celebra a su Señor.

Como ya pasó al enunciar la dimensión del conocimiento de la fe, el documento baja a detalles en el momento de hacer el planteamiento teórico. Esto indica la preocupación de los obispos ante algunos aspectos de celebración generalizados, como "la expresividad corporal que no es adecuadamente respetuosa del clima religioso que debe caracterizar la auténtica celebración" (CC n. 90).

- Iniciación en el compromiso apostólico y misionero de la Iglesia (CC n. 91-92). Se trata de iniciar en un aspecto esencial de la fe cristiana: capacitar para una presencia cristiana en la sociedad (vida profesional, cultura, sindical, política...) con inspiración evangélica. También en las tareas de la comunidad (catequistas, animador litúrgico, acogida, obras de servicio...), todo lo que construye la comunidad eclesial.

Finalmente conviene destacar dos elementos de la comprensión de la catequesis:

- Su carácter de fundamentación: Es propio de la catequesis "sentar las bases de la fe y de la consolidación de la fe" (CC n. 97). No se le pide a la catequesis todo. Solo lo que es el fundamento de una vida cristiana que necesitará una edificación progresiva dentro de la comunidad.

- El carácter temporal del proceso catequético. La catequesis es un proceso que empieza y termina (Cfr. $C C$ n. 101) por ser "iniciación" a la vida de la comunidad.

Al elaborar este marco teórico sobre la catequesis extrayendo los elementos fundantes de la catequesis a partir del catecumando bautismal de adultos no bautizados, es lógico que sean necesarias "adaptaciones" a las realidades pastorales de las comunidades cristianas, por ejemplo, destinatarios bautizados, ya sean niños y jóvenes en procesos de preparación para un sacramento, o bautizados adultos alejados, indiferentes... En cualquier etapa de la vida es posible que la persona, por las circunstancias que sean, necesite una catequesis. Por eso se habla de una catequesis de "inspiración 
catecumenal" y no de un "catecumenado" (cfr. CC. n. 105). Dadas las pautas generales de lo que se entiende por catequesis se podrán hacer adaptaciones concretas.

Se advierte, además, una cierta confusión en la parte Carácter propio de la catequesis (CC n. 77-151) cuando se ponen en este momento apartados como: Fundamento del carácter propio de la catequesis en la constitución “Dei Verbum” (CC n.106-139) o El carácter propio del lenguaje catequético (CC 140-151) que presentan aspectos más propios de criterios de realización del acto catequético. Pero estamos en los orígenes ${ }^{51}$. Todo ello lleva a que en la definición de catequesis se incluyan aspectos que deberían separarse y agruparse más como criterios pedagógicos.

\section{LA FIGURA DEL CATEQUISTA}

En el documento La Iglesia y la educación en España hoy (1969) se dedica el capítulo quinto a Instituciones y personas ante la educación de la $f e(I I)^{52}$. Es una reflexión general sobre el educador cristiano que tiene muy en cuenta el ámbito escolar y la educación en la fe que en ese momento realiza la Iglesia. Hay que esperar mucho tiempo para tener un documento específico sobre el profesor de religión ${ }^{53}$. Es cierto que entre líneas, y utilizando referencias de varios pronunciamientos y documentos del Episcopado

\footnotetext{
${ }^{51}$ Sería un buen trabajo de investigación comparar La catequesis de la comunidad con el Directorio General para la Catequesis (1997) y ver las coincidencias y los cambios. Digo esto teniendo en cuenta que ambos documentos tuvieron a don José Manuel Estepa como uno de los artífices. De todas formas, esta apreciación está al margen del objeto propio de este trabajo.

${ }^{52}$ Comisión Episcopal de Enseñanza y Educación Religiosa, La Iglesia y la educación en España hoy, en "Documentos colectivos del Episcopado Español sobre formación religiosa y educación”, Edice, Madrid 1981, pp.21-114. El capítulo al que nos referimos ahora, cfr. pp. 53-65. Hay que advertir que el capítulo cuarto lleva el mismo título, es en la primera parte donde se abordan temas como la comunidad cristiana familiar, la comunidad cristiana escolar, asociaciones y movimientos educativos, la comunidad cristiana local diocesana y universal. Sin entrar en más estudio, los títulos indican la realidad del momento y una educación en la fe muy ligada a las instituciones tradicionales de la familia, escuela, iglesia. Aunque se añaden ya las asociaciones y movimientos educativos.

${ }^{53}$ Comisión Episcopal de Enseñanza y Catequesis, El profesor de Religión católica. Identidad y misión, Madrid 1998. https://www.conferenciaepiscopal.es/wp-content/uploads/2018/07/1998_profesor_religion_catolica_identidad_y_mision.pdf
} 
español ${ }^{54}$, se puede sacar un perfil del profesor de religión, pero sin que exista un documento específico.

\section{El documento El catequista y su formación: la realidad del momento eclesial}

A solo dos años de la publicación de La catequesis de la comunidad, sale un documento sobre la figura del catequista y sobre su formación ${ }^{55}$. Esta observación parece pertinente porque no ocurre lo mismo con el profesor de religión. Nos preguntarnos por qué esta rapidez. Creemos que existe un conjunto de síntomas que explican la premura. La misma introducción de El catequista y su formación, así como el contenido de su primera parte Realidad de los catequistas en la Iglesia española, hoy (n 1-14) nos proporcionan no pocos indicios de respuesta. Recogemos algunos a continuación:

- El maestro-catequista poseía una formación intelectual, pedagógica específica de cara al ejercicio de su misión como maestro, además de una preparación en el campo de la enseñanza religiosa. El catequista de la comunidad pasa a serlo por el simple hecho de ofrecerse "a ser catequista", sin otra preparación previa "académica" específica que su experiencia de vida cristiana, su experiencia de lo que han hecho con él en la catequesis, lo que ve hacer, el libro que ponen en sus manos, la preparación inmediata para la sesión de catequesis, la formación "autodidacta" que él emprenda responsablemente. Más aún, no dispone de un ámbito reconocido de formación específica ${ }^{56}$.

- Al hablar de las sombras que oscurecen la realidad de los catequistas, $C F$ nos proporciona una información interesante (cfr. n. 6): demasiados catequistas jóvenes faltos de madurez humana y cristiana; ser catequista es "un tiempo muy transitorio" (lo cual implica que no se

\footnotetext{
${ }^{54}$ Por poner un ejemplo, Conferencia EPISCOPAl EsPañola, La educación en la fe del pueblo español. Proposición aprobada por la XX Asamblea Plenaria de la Conferencia Episcopal Española, 22 de junio de 1974.

${ }^{55}$ Comisión Episcopal de EnseñanZa y CATEQuesis, El catequista y su formación. Orientaciones pastorales, Edice, Madrid 1985. En adelante lo citamos como CF.

${ }^{56}$ Con este juicio de valor no queremos negar el trabajo de las escuelas de catequistas locales, diocesanas y de rango más universitario. Hay que reconocer que no hay comparación entre este tipo de escuelas y los Centros de Formación del Profesorado.
} 
acumula experiencia pedagógica), ser catequista es la única salida que se da a los jóvenes, se "da catequesis" pero no se es catequista, se "da la catequesis nocional de preguntas y aprendizaje" no la que propone el documento de la Catequesis de la comunidad con sus dimensiones o tareas propias.

- La visita del Papa a España (1983) suscita un movimiento de necesidad de servicio a la fe de nuestro pueblo ${ }^{57}$, a la educación en la fe del pueblo de Dios. Aquí es donde hay que situar la reflexión sobre la identidad del catequista y su formación.

- Los obispos tienen la convicción de que en la acción catequizadora de la Iglesia, el catequista es el agente más importante. "El Evangelio que la Iglesia anuncia en la catequesis se hace mensaje de vida en el pueblo cristiano por medio de la mente, del corazón, de la sensibilidad, de la palabra y de la vida de fe del catequista" ( $C F$ introducción). Si este agente de la catequesis no posee una identidad y una formación específica, la acción catequizadora no logrará realizar su misión.

\section{Aspectos de la identidad del catequista}

La primera constatación que el lector percibe es la complementariedad de El catequista y su formación con el documento La catequesis de la comunidad. Los ejes fuertes del $C F$ están concentrados en determinar la identidad del catequista y su formación para la misión.

La parte del documento dedicada a la identidad del catequista ( $C F \mathrm{n}$. 15-87) tiene, a su vez, dos partes bien distintas: el servicio catequético (CF n. 16-46) y la vocación del catequista (CF n. 47-87).

$\mathrm{El}$ análisis del texto nos hace ver que la identidad del catequista no puede ser entendida sin considerar bien dónde ejerce su actividad dentro de la misión evangelizadora de la Iglesia. Lo que el catequista está llamado a hacer (una tarea dentro del proceso evangelizador de la Iglesia) marca su identidad y su espiritualidad en la Iglesia ( $C F$ n. 61). Además, hay que perfilar una identidad que no dimana para la gran mayoría de los catequistas

${ }^{57}$ Conferencia Episcopal Española, La visita del Papa y el servicio a la fe de nuestro pueblo. Programa pastoral de la conferencia Episcopal, Edice, Madrid 1983. IDEM, El servicio a la fe de nuestro pueblo, Edice, Madrid 1983. Dos documentos íntimamente relacionados. https://conferenciaepiscopal.es/documentos/Conferencia/visita_papa.htm 
del sacramento del Orden, sino sencillamente de su vocación bautismal. Hay catequistas especiales por el sacramento del Orden recibido, como el obispo, el presbítero, el diácono. Pero, ¿cuál es la identidad del catequista seglar de una comunidad cualquiera? A esta pregunta se responde con estos núcleos identitarios.

\subsection{El servicio catequético tiene su lugar en el proceso de evangelización}

La primera preocupación que muestra $C F$ es dejar claro que cada una de las acciones del proceso de evangelización, que es la misión de la Iglesia, exige un servicio por parte de miembros de la comunidad. Este servicio o ministerio se realiza según el modelo de servicio inaugurado por Jesús que "no vino a ser servido sino a servir" $(M t 20,28)$.

La argumentación del servicio de la catequesis en la Iglesia parte de lo que Pablo VI propone en Evangelii nuntiandi: "Es cierto que al lado de los ministerios con Orden sagrado, en virtud de los cuales algunos son elevados al rango de Pastores y se consagran de modo particular al servicio de la comunidad, la Iglesia reconoce un puesto a ministerios sin orden sagrado, pero que son aptos a asegurar un servicio especial a la Iglesia" 58 .

El reconocimiento de ministerios o servicios en el seno de la Iglesia depende de echar una mirada a la vida de la Iglesia a lo largo del tiempo y de prestar atención a las necesidades actuales de la humanidad y de la Iglesia. Los obispos españoles hablan de "servicio de catequesis", "servicio de catecumenado" y "servicio de enseñanza religiosa" ( $C F$ n. 26). Estos tres servicios pertenecen a la acción catequizadora de la Iglesia ${ }^{59}$. Resulta al

${ }^{58}$ Evangelii nuntiandi n. 73. Es significativo que en $C F$ los obispos sientan la necesidad de esclarecer en nota, por si no fuera suficiente lo que dice Evangelii nuntiandi, la distinción entre ministerios con orden sagrado y los ministerios sin orden sagrado que pueden ser asumidos por religiosos no sacerdotes y por los seglares. Dentro de estos ministerios sin orden sagrado, hay unos que son instituidos con carácter estable mediante un rito litúrgico, y hay otros ministerios no instituidos como "oficios eclesiales" (c. 226), "encargos" (c. 228), y "servicios" (c. 231) con dedicación permanente o temporal. Es posible que las matizaciones haya que entenderlas en el sentido de que, hasta el día de hoy, el catequista no es un servidor ordenado instituido. De todas formas, se sigue hablando del "ministerio del catequista". En algunos lugares (algunas Iglesias de Latinoamérica, al curso de formación de catequistas lo denominan "Formación para el ministerio del catequista": https://palabrayobra.org.mx/palabrayobra.org.mx/Formacion_Catequistas.html

${ }^{59}$ La inclusión del servicio de enseñanza religiosa en la acción catequizadora sigue mostrando la tendencia a la "catequesis escolar" que ya hemos visto. Creemos que en la realidad habría que situar este servicio más en la "acción misionera de la Iglesia". 
menos curioso en $C F$ que una vez situado y denominado como "servicio de catequesis", "servicio catecumenal" ( $C F$ n. 26) se hable inmediatamente del "carácter propio del ministerio o servicio catequético". Me inclino a pensar que tanto la denominación de ministerio catequético como la de servicio catequético son expresiones verdaderas en el conjunto de la Iglesia, aunque la Iglesia española opte por la expresión servicio.

\subsection{El servicio catequético recibe la originalidad que le da el lugar que ocupa al interior del proceso de evangelización}

Es propio en el servicio catequético, y por tanto del miembro de la comunidad que lo realiza, la inspiración catecumenal de la catequesis. Con otras palabras: el catequista no tiene por qué ser un doctor. Su originalidad es más básica: poner los fundamentos sobre los que se edifique progresivamente el edificio de la fe. "La tarea propia del catequista consiste en hacer madurar la conversión inicial hasta hacer de ella una viva, explícita y operante confesión de fe ${ }^{60} "$.

\subsection{El servicio catequético es un servicio eclesial}

Esta afirmación abarca muchos matices. El sujeto de la responsabilidad de la acción catequética es la comunidad cristiana. Ella es origen y meta: de la comunidad sale la pasión por la misión evangelizadora; y esta misión incorpora a la comunidad a quienes el Espíritu llama. Desde esta óptica, es impensable un catequista que no esté en comunión con la comunidad. Es esencia del catequista su sentido eclesial, su vivencia de la fe en la comunidad. "La acción catequética transmite el Evangelio tal como es creído, celebrado y vivido por la Iglesia" ( $C F$ n. 33). No se catequiza "por libre", al margen de la comunión eclesial. Catequizar es un servicio público de la Iglesia, por eso los catequistas reciben la misión para catequizar. El catequista está entroncado en una tradición viva, es un eslabón de la tradición que viene de los apóstoles ( $C F$ n. 68-70) y que vive en comunidad ( $C F$ n. $72-$ 73) para el servicio de todos los hombres ( $C F \mathrm{n}$. 75-76). No amar y valorar lo humano, no sintonizar con los gozos y alegrías de la humanidad es señal de falta de vocación.

${ }^{60} C F$ n. 33 que a su vez cita La catequesis de la comunidad, n. 96. 


\subsection{El servicio catequético es una tarea común y diferenciada}

La catequesis es una responsabilidad común de toda la Iglesia en la que participan sacerdotes, religiosos y seglares "pero de manera diferenciada, cada uno sobre la base de su particular condición (ordenación, vida consagrada o carácter laical) ... sin la colaboración de religiosos y de los seglares o la iniciativa de los sacerdotes la catequesis se resentiría y carecería de toda su riqueza y significado" $(C F \mathrm{n} .34)^{61}$.

\subsection{El catequista es un vocacionado}

La lógica de la identidad del catequista elegida por $C F$ comienza por describir el servicio que este tiene que realizar y termina por la vocación. Este orden lógico, que muy bien pudiera ser invertido, muestra la prioridad dada a la tarea para la que se es llamado.

Ser catequista es una vocación que Dios hace a determinados cristianos por su condición de bautizados. No es un simple gusto o "lo que apetece" hoy, y mañana no. Hablar de vocación es hablar de respuesta, de realizar una tarea que va más allá de todo lo que es ensayo o un tiempo para probar. La dimensión vocacional sitúa al catequista en la órbita de la gracia, de la iniciativa de Dios que sobrepasa totalmente la sola "planificación" personal ( $C F$ n. 48-51).

La vocación del catequista tiene un modelo en lo que Jesús hizo en su tarea de enseñar con autoridad ( $C F$ n. 53-54) y en su asumir el paso por el misterio pascual ( $C F \mathrm{n}$. 53-56). Así mismo, la vocación del catequista pide una apertura al Espíritu Santo como principal agente de la evangelización. El Espíritu es el primer maestro interior tanto del catequista como de los catequizandos: "Él es quien explica a los fieles el sentido profundo de las enseñanzas de Jesús y su misterio" (EN n. 75).

${ }^{61}$ Pasa el documento $C F$ a señalar algunos aspectos de los catequistas según sean seglares (n. 35-37), religiosos (n. 38-39), sacerdotes (n. 40-42), obispo (n. 43-46). Esta panorámica de descripción de los agentes catequistas es importante, orienta y sitúa el funcionamiento ordinario práctico de la catequesis en colaboración y en comunión. Adelantemos ya que El catequista y su formación en los aspectos concretos de la formación mira más a los catequistas seglares. Por lo general, religiosos y sacerdotes poseen una formación institucional teológica y bíblica. No siempre esta formación es garantía de una formación específica catequética (así muchos sacerdotes no cursan en su currículo la disciplina de la Catequética aunque después sean maestros y educadores de la fe en las comunidades). El verdadero problema de la formación de catequistas son los catequistas seglares. 
Por ser vocacionado, el catequista, en aquello que tiene que hacer, encuentra una fuente de espiritualidad, es decir, una configuración de su vida cristiana y su vivencia de la fe, de la esperanza, de la caridad, de la escucha y de la contemplación de la Palabra de Dios (CF n. 61-66).

\section{LA FORMACIÓN DEL CATEQUISTA}

La lógica de los obispos en este documento es coherente. No basta delinear un perfil de la identidad del catequista, son necesarias orientaciones para una formación de catequistas que se encaminen a alcanzar la madurez y la capacitación específicas para catequizar.

Se proponen como principios inspiradores de la formación de catequistas:

\subsection{Dimensión eclesiológica}

- La acción del catequista se realiza en la comunidad cristiana que forma parte de la Iglesia particular, en comunión con la Iglesia Universal. Se cultiva así la inserción y carácter diocesano concreto de los catequistas ( $C F$ n. 90).

- El catequista realiza su tarea evangelizadora específica junto a otros agentes de las diversas acciones pastorales. Hay aquí una intuición importante de la formación de agentes de evangelización dentro de la Iglesia particular con un tronco común igual para todos y con el cultivo de la diversidad que viene de la tarea a realizar. El centro es la importancia de la Iglesia particular responsable de coordinar y de velar por la formación de los agentes de evangelización ( $C F$ n. 91). Hay que notar aquí que este planteamiento se dirige sobre todo a catequistas más estables, como a agentes de evangelización con estabilidad en su función. De todas maneras, el mismo texto admite que la ventaja de esta formación con otros agentes "no es tan evidente en nuestras Iglesias" y que con los catequistas voluntarios -que son los más- quizás, por muchas razones, entre otras prácticas: distancia, desplazamientos, temporalidad, posibilidades reales, a lo mejor "resultaría más aconsejable que se hiciera por separado". Es decir, a la vez se apunta a un ideal y se es consciente de las dificultades o hasta de su imposibilidad. 
- La formación tiene que ser realista, según las necesidades de la Iglesia particular. Se critica la formación de catequistas realizada "a partir de unos programas prefijados y destinado a un tipo de comunidad cristiana y un tipo de catequesis que no se corresponde con las condiciones reales que existen y pueden existir en las diócesis a que deben servir" ( $C F$ n. 92).

- La dimensión eclesiológica pide, también, no perder de vista la pastoral de catequistas que es más amplia que la formación de catequistas. La pastoral de catequistas conlleva aspectos como suscitar vocaciones, acompañamiento personal, etc. ( $C F$ n. 95).

\subsection{Dimensiones que debe cultivar la formación de catequistas}

Uno está tentado de pedir más claridad al documento $C F$ en las dimensiones o facetas o áreas concretas de la formación de catequistas. Se dicen muchas cosas, pero un poco dispersas. De la lectura de propuestas creo que se pueden sintetizar estos núcleos.

- El hombre y el mundo de hoy ${ }^{62}$. Apertura a los problemas y deseos de la persona y a la realidad del mundo en que vivimos. Ser capaces de situarse de manera positiva para saber percibir los signos de los tiempos, que son signos de Dios. En definitiva, es la invitación de Gaudium et spes n. 1: "Los gozos y las esperanzas, las tristezas y las angustias de los hombres de nuestro tiempo". Aquí hay un gran apoyo en las ciencias del hombre.

- La persona misma del catequista: dimensión humana y cristiana. Si ser catequista es una vocación dentro de la comunidad cristiana en la Iglesia particular hay que cultivar el ser del catequista: sus motivaciones, su respuesta a la llamada del Señor, su vida de creyente, su experiencia cristiana que tiene concreciones en la oración, la celebración, la vida cristiana de cada día ${ }^{63}$. Difícilmente acompañará la maduración en la fe de otros quien no tiene una vivencia de maduración personal en la fe, sin disociar fe y vida, sino una fe hecha vida en el cada día.

- Capacidad para dar razón de la fe. Es decir, todo aquello que da razón de la propia fe y se convierte en cimiento sólido del edificio de la fe

\footnotetext{
${ }^{62}$ Cfr. $C F$ n. $75-77.115-117$.

${ }^{63}$ Cfr. $C F$ n. $78.85-86.100$.
} 
estructurada para la persona y para aquellos a los que se catequiza. Lo que el catequista anuncia no es algo exterior a él o que no le concierna $^{64}$. Si anuncia es porque está concernido por la fe que proclama. Aquí hay aspectos como: el concepto de catequesis, de Iglesia particular, de teología y biblia, de psicología de las personas y sus procesos de acogida y maduración...

- Capacitación para el saber hacer ${ }^{65}$. El catequista tiene un momento en el que se enfrenta a unas personas, ya sea en grupo o de manera individual y tiene que "saber hacer". Además de las aportaciones de las ciencias pedagógicas y psicológicas, tendrá que tener muy en cuenta, la "pedagogía divina" (=el lento revelarse de Dios en la historia que culmina en Jesús, el Mesías) y la "pedagogía de la Iglesia" (que a lo largo de los tiempos ha ido "evangelizando desde las más diversas realidades", aprendiendo y manteniendo siempre los ojos puestos en su Maestro, y el oído atento a su Espíritu el encargado de enseñarnos la hondura de las palabras y gestos del Señor.

En estas dimensiones hay, creo, tres preocupaciones que lo resumen todo. El catequista es una persona situada en un mundo, con unos hombres concretos e históricos que necesita cultivar su ser, su saber y su saber hacer. Estas son las líneas de fuerza que están detrás de la formación de los catequistas.

\section{CONCLUSIÓN}

El "momento fuerte" de la historia de la catequesis postconciliar en España está concentrado en unos pocos años densos de vida eclesial ${ }^{66}$, la

${ }^{64}$ Cfr. $C F$ n. 83.87.96-98.108-114

${ }^{65}$ Cfr. $C F$ n. $115-120$.

${ }^{66}$ La etapa más creativa postconciliar en lo tocante a la catequesis, está sin duda entre los años 1969-1990. Además de los documentos ya mencionados, no podemos dejar de citar, si bien no lo tratamos, la aparición del catecismo de Preadolescentes Con vosotros está, Edice, Madrid 1976. Su importancia no está tanto en cómo fue acogido por la comunidad cristiana (que no estaba preparada para un cambio tan repentino del catecismo escolar al nuevo modelo de catecismo), sino en lo que supuso su elaboración como mentalización catequética del episcopado español (1972-1976) y en el volumen de trabajo catequético elaborado: 4 vol. del catecismo; 3 vol. del Manual del educador; 2 vol. Manual del educador. Guía doctrinal: 3 
que el Vaticano II impulsó, y la que la sociedad española y, con ella, la Iglesia de España, tuvieron que afrontar. Fueron años convulsos en la sociedad española: la tarea (¡y prisa!) por salir de un régimen político sin libertades y abrirse a una democracia anhelada y esperada. Estos dos elementos: el postconcilio eclesial y el sociopolítico son los que explican los cambios y la forma vertiginosa de realizarnos: salir de una "catequesis escolar" a una diversificación entre enseñanza religiosa y catequesis.

Con admiración y humildad hay que reconocer lo que se hizo y lo bien que se hizo. Esto no quiere decir que la Iglesia española asumiera en las bases de las comunidades cristianas los cambios que se producían. Pero hubo un planteamiento teórico de calado que solo con el tiempo podrá ser apreciado y justamente valorado.

Esta aportación, en el homenaje al querido amigo Luis Resines, solo ha querido presentar el hilo lógico de los cambios centrado exclusivamente en los documentos intrínsecos de la Iglesia. Una explicación más exhaustiva queda pendiente prestando atención al diálogo que se entabló, sobre todo a nivel de declaraciones y comunicados entre la Iglesia española y la sociedad española.

Las intuiciones y definiciones de escuela, enseñanza religiosa, catequesis que entonces maduraron siguen siendo vigentes hoy. Hay que reconocer que ya se apuntan nuevas realidades en el horizonte para responder a una sociedad nueva, a un cambio de época, donde la Iglesia perderá poder de referencia y de significatividad. Sin embargo, el Evangelio que ella tiene que anunciar se lo tendrá que aplicar primero a sí misma y, rejuvenecida, lo ofrecerá a quienes sean tocados por el Espíritu. Esta historia vivida permanecerá como ejemplar paradigma de cambio.

vol. La Biblia de la lniciación cristiana. Sin contar las adaptaciones hechas para la escuela. En el futuro bien merecería ser estudiado con detenimiento. 